\title{
Molluscan Memory of Injury: Evolutionary Insights into Chronic Pain and Neurological Disorders
}

\author{
Edgar T. Walters ${ }^{\mathrm{a}}$ Leonid L. Moroz ${ }^{\mathrm{b}}$ \\ ${ }^{a}$ Department of Integrative Biology and Pharmacology, University of Texas Medical School at Houston, \\ Houston, Tex., and bepartment of Neuroscience and McKnight Brain Institute, Gainesville, Fla., and \\ Whitney Laboratory for Marine Bioscience, University of Florida, St. Augustine, Fla., USA
}

\section{Key Words}

Aplysia • Evolution • Gene loss • Genome • Injury • Nociceptive sensitization $\cdot$ Memory $\cdot$ Neurological disorders - Pain

\begin{abstract}
Molluscan preparations have yielded seminal discoveries in neuroscience, but the experimental advantages of this group have not, until now, been complemented by adequate molecular or genomic information for comparisons to genetically defined model organisms in other phyla. The recent sequencing of the transcriptome and genome of Aplysia californica, however, will enable extensive comparative studies at the molecular level. Among other benefits, this will bring the power of individually identifiable and manipulable neurons to bear upon questions of cellular function for evolutionarily conserved genes associated with clinically important neural dysfunction. Because of the slower rate of gene evolution in this molluscan lineage, more homologs of genes associated with human disease are present in Aplysia than in leading model organisms from Arthropoda (Drosophila) or Nematoda (Caenorhabditis elegans). Research has hardly begun in molluscs on the cellular functions of gene products that in humans are associated with neurological diseases. On the other hand, much is known about molecular and cellular mechanisms of long-term neuronal plasticity. Persistent nociceptive sensitization of nociceptors in Aplysia
\end{abstract}

displays many functional similarities to alterations in mammalian nociceptors associated with the clinical problem of chronic pain. Moreover, in Aplysia and mammals the same cell signaling pathways trigger persistent enhancement of excitability and synaptic transmission following noxious stimulation, and these highly conserved pathways are also used to induce memory traces in neural circuits of diverse species. This functional and molecular overlap in distantly related lineages and neuronal types supports the proposal that fundamental plasticity mechanisms important for memory, chronic pain, and other lasting alterations evolved from adaptive responses to peripheral injury in the earliest neurons. Molluscan preparations should become increasingly useful for comparative studies across phyla that can provide insight into cellular functions of clinically important genes.

Copyright $\odot 2009$ S. Karger AG, Basel

\section{Introduction}

Mollusca, the second largest animal phylum after Arthropoda, has contributed influential experimental preparations to neuroscience. Large, identifiable neuronal somata and axons in selected molluscs have been exploited as 'model systems' to reveal basic mechanisms of neuronal function and plasticity, with some of these discoveries becoming foundations of neurophysiology [Gilbert et al., 1990; Kandel, 2001; Chase, 2002]. Until recently, however,

\section{KARGER}

(C) 2009 S. Karger AG, Basel

Fax +4161306 1234

E-Mail karger@karger.ch

www.karger.com
Accessible online at:

www.karger.com/bbe
Edgar T. Walters, $\mathrm{PhD}$

Department of Integrative Biology and Pharmacology

University of Texas Medical School at Houston, 6431 Fannin St, MSB 4.116

Houston, TX 77030 (USA)

Tel. +1 713500 6314, Fax +1 713500 7444, E-Mail edgar.t.walters@uth.tmc.edu 
little could be said about how the neural and behavioral phenomena described in molluscs were related evolutionarily to formally similar phenomena in humans. A major limitation was a paucity of the molecular and genomic information needed to identify conserved genes and lineage-specific innovations in molluscs. Moreover, although much research on molluscan nervous systems has been supported by agencies devoted to human health, few studies have explicitly investigated molluscan counterparts of clinically important processes. Nonetheless, some of the basic neuronal mechanisms and associated genes being described in molluscs appear to have functional and/or molecular equivalents that are of considerable clinical significance in humans. Here we consider the use of molluscs to explore conserved and convergent mechanisms that might contribute to selected clinical problems, with particular emphasis on the problem of chronic pain and the possible role of evolutionarily conserved mechanisms shared with memory.

\section{Molluscan Neurogenomics}

The divergence among major bilaterian lineages probably occurred in the Upper Precambrian period (at least 550 million years ago) [Valentine, 2004]. Comparisons of molluscs to other lineages have been slowed, however, by a lack of genetically tractable models and a dearth of genomic information about this phylum. Genome-wide information from at least 2-3 molluscan species is needed to establish evolutionary relationships between molluscan and mammalian genes, molecular pathways, and their functions. Recently the first genomic information from a mollusc became available, with the publication of the neuronal transcriptome and mitochondrial genome of the opisthobranch gastropod, Aplysia californica [Knudsen et al., 2006; Moroz et al., 2006]. This enabled genome-scale profiling of individual, functionally characterized neurons and isolated neuronal processes, opening the way for analyses of the genomic bases of neuronal identity and plasticity in uniquely identified cells. In parallel, the Aplysia genome project was initiated [Moroz et al., 2004], and by 2008 the first stage of sequencing of this genome was completed (http://www.ncbi.nlm.nih.gov/ nuccore/AASC00000000.2). In addition, the compact genome of a limpet, Lottia gigantea (in the basal gastropod lineage), has also been sequenced (unpublished, see http://genome.jgi-psf.org/Lotgi1/Lotgil.info.html), providing an important comparative reference. These advances complement well-known neurophysiological ad- vantages of Aplysia with the ability to specify large gene groups involved in phenomena of interest and to discern patterns of evolution involving these gene products both in molluscs and across phyla.

\section{Aplysia Neurogenomics, Evolution, and Genes Related to Neurological Diseases}

Prominent among the experimental advantages that have established Aplysia as a leading model system for analyzing cellular bases of behavior and plasticity [Kandel, 1976, 2001] are its relatively simple CNS of nine central ganglia containing only about 10,000 neurons [Cash and Carew, 1989], many of which are readily identifiable by soma size and location (fig. 1), electrophysiological properties (fig. 2), synaptic connections (fig. 2) and behavioral effects. More than 200 neurons and hundreds of monosynaptic connections have been individually identified in feeding, locomotor, respiratory, and defensive systems. Compared to Drosophila melanogaster and Caenorhabditis elegans, the two dominant models in molecular neurobiology, three features distinguish Aplysia as a model system: its large neurons, the relatively slow rate of evolution of genes in this lineage (with preservation of an ancestral subset of gene homologs linked to human diseases), and its use of DNA methylation for transcriptional regulation.

The giant sizes of opisthobranch and pulmonate neuronal somata (200-600 $\mu \mathrm{m}$ somata are common) and growth cones (sometimes $>600 \mu \mathrm{m}$ ) [Lovell et al., 2006; Lovell and Moroz, 2006] contrast dramatically with those of C. elegans and Drosophila, in which most somata are only 2-5 $\mu \mathrm{m}$ in diameter. Large, individually identifiable neurons facilitate combined physiological, microchemical and genomic measurements [Kandel, 2001; Moccia et al., 2003; Drake et al., 2005; Jezzini et al., 2005; Moroz et al., 2005, 2006; Lovell et al., 2006]. Although giant neurons are also found in other groups (e.g., leeches and crustaceans), the cell bodies of gastropod neurons are fully excitable and, despite their large size, these neurons are electrotonically compact [Adams et al., 1980], permitting unequalled intracellular recordings of synaptic and action potentials from the somata (sometimes simultaneously from multiple neurons in vivo or in vitro for hours at a time). Moreover, the large neurons tolerate repeated microelectrode impalements over several days. These features help drive advances not only in linking neuronal properties to behavior, but in understanding the general cell biology of neurons. For example, neurons from Aplysia and other molluscs have provided insights into axonal 
A
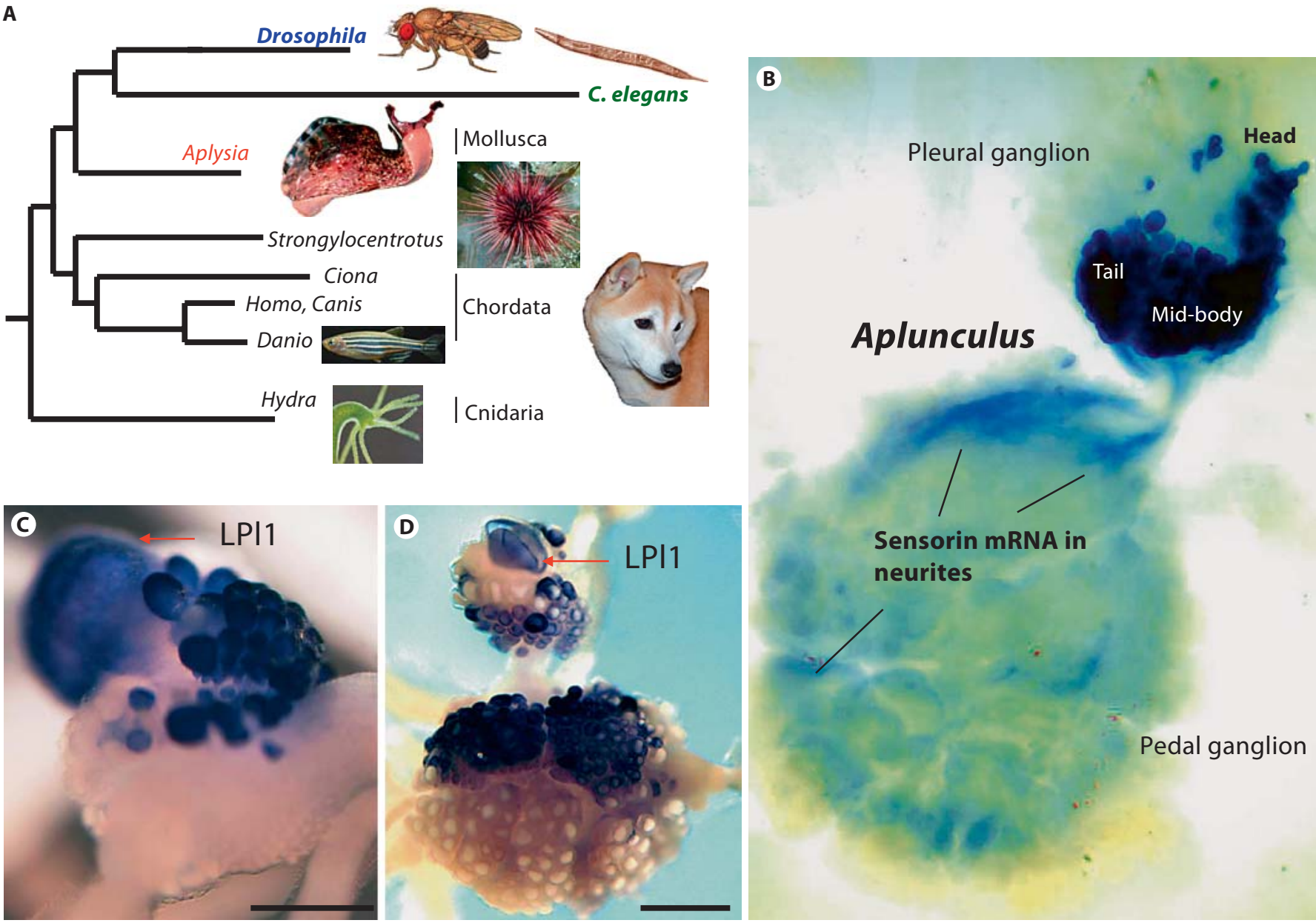

Motor neurons (Huntingtin, ACh)

Sensory neurons (Sensorin)

Fig. 1. Features of a molluscan model organism, Aplysia californica. A Phylogenetic relationships of gastropods (Aplysia) to other prominent model organisms: insects (Drosophila), nematodes (Caenorhabditis elegans), sea urchins (Strongylocentrotus), ascidians (Ciona), vertebrates (represented by dog, Canis, and zebrafish, Danio), and cnidarians (hydrozoan Hydra). The evolutionary distance (indicated as relative branch length) from Canis or Danio to Aplysia is shorter than the distance from the vertebrates to Drosophila or C. elegans, suggesting that the amino acid replacement rate has been lower in the lineage leading to the gastropod Aplysia than in the lineages leading to Drosophila and C. elegans. B Nociceptive sensory neurons in the right ventrocaudal
(VC) cluster revealed by in situ hybridization staining for a sensory neuron-specific neuropeptide, sensorin. A somatotopic map ('Aplunculus') of the ipsilateral body surface is represented in the cluster. Note that sensorin mRNA is found in neurites and axons throughout the pedal ganglion. C Expression of huntingtin occurs in the giant mucus release motor neuron, LPl1, and other neurons in the left pleural ganglion (in situ hybridization). Scale: $450 \mu \mathrm{m}$. D In situ hybridization shows choline acetyltransferase mRNA (a marker for cholinergic neurons) in diverse neurons, including LPl1, in the left pleural and pedal ganglia. Panels $\mathbf{A}, \mathbf{C}$ and $\mathbf{D}$ are modified from Moroz et al. [2006]; panel B is modified from Walters et al. [2004]. regeneration [e.g., Gitler and Spira, 1998; Erez and Spira, 2008], and the cellular functions of human molecules related to disorders such as Alzheimer's disease, which are being illuminated by testing the effects of injections (e.g., of amyloid precursor protein, beta-amyloid peptide, tau) into giant gastropod somata and cephalopod axons [Sat-
pute-Krishnan et al., 2003; Samarova et al., 2005; Shemesh et al., 2008].

The number of gene homologs shared by mammals with molluscs is greater than the number shared by mammals with Drosophila or C. elegans. Phylogenetic analyses (fig. 1A) position Aplysia as a sister group to the arthro- 
Table 1. Selected examples of Aplysia homologs of human genes relevant to neurological diseases, with comparisons to other genomic models in Metazoa. The genes marked by asterisks $\left(^{*}\right)$ illustrate predicted cases of gene loss in one $\left(^{*}\right)$ or more $\left({ }^{*}\right)$ lineages of bilaterian animals. The numbers below each organism name indicate the E value ${ }^{1}$ for comparison of predicted homologous proteins using the standard BLAST search

\begin{tabular}{|c|c|c|c|c|c|c|}
\hline Gene symbol & ID & Human disease name, OMIM No. and chromosome location & Aplysia & Drosophila & C. elegans & Hydra \\
\hline PSEN2 & NM_000447 & Alzheimer disease, familial, early-onset PSEN2 600759 1q31-q42 & $9.00 \mathrm{e}-98$ & $6.00 \mathrm{e}-79$ & $2.00 \mathrm{e}-61$ & $3.00 \mathrm{e}-69$ \\
\hline NTRK1 & NM_002529 & Insensitivity to pain, congenital, with anhidrosis NTRK1 191315 1q21-q22 & $4.00 \mathrm{e}-46$ & $3.00 \mathrm{e}-67$ & $2.00 \mathrm{e}-54$ & $3.00 \mathrm{e}-44$ \\
\hline FMR1* & NM_002024 & Fragile X syndrome FMR1 309550 Xq27.3 & $3.00 \mathrm{e}-46$ & $9.00 \mathrm{e}-70$ & - & $2.00 \mathrm{e}-36$ \\
\hline $\mathrm{HD}^{*}$ & NM_002111 & Huntington disease HD $1431004 \mathrm{p} 16.3$ & $9.00 \mathrm{e}-55$ & $5.00 \mathrm{e}-16$ & - & - \\
\hline $\operatorname{CSTB}^{* *}$ & NM_000100 & Epilepsy, progressive myoclonic type 1 CSTB 601145 21q22.3 & $7.00 \mathrm{e}-28$ & - & - & $2.00 \mathrm{e}-25$ \\
\hline SMN1** & NM_000344 & Spinal muscular atrophy type 1 SMN1 600354 5q12.2-q13.3 & $5.00 \mathrm{e}-20$ & - & - & $2.00 \mathrm{e}-16$ \\
\hline UCHL1 & NM_004181 & Parkinson disease UCHL1 191342 4p14 & $6.00 \mathrm{e}-41$ & $1.00 \mathrm{e}-35$ & $2.00 \mathrm{e}-07$ & $7.00 \mathrm{e}-13$ \\
\hline MAPT & NM_005910 & Dementia, frontotemporal, with parkinsonism MAPT 157140 17q21.1 & $2.00 \mathrm{e}-24$ & $3.00 \mathrm{e}-12$ & $2.00 \mathrm{e}-16$ & - \\
\hline TTPA* & NM_000370 & Ataxia with isolated vitamin E deficiency TTPA 600415 8q13.1-q13.3 & $2.00 \mathrm{e}-26$ & $4.00 \mathrm{e}-27$ & - $\quad$ & $4.00 \mathrm{e}-09$ \\
\hline ATM $^{*}$ & NM_138293 & Ataxia-telangiectasia ATM 208900 11q22.3 & $2.00 \mathrm{e}-06$ & - $\quad$ & $1.00 \mathrm{e}-23$ & - \\
\hline UBE3A* & NM_130839 & Angelman syndrome UBE3A 601623 15q11-q13 & $1.00 \mathrm{e}-175$ & $1.00 \mathrm{e}-145$ & - $\quad$ & $1.00 \mathrm{e}-88$ \\
\hline FCMD $^{*}$ & NM_006731 & Fukuyama congenital muscular dystrophy FCMD 253800 9q31-q33 & $2.00 \mathrm{e}-06$ & - & $1.00 \mathrm{e}-34$ & - \\
\hline KIF1B & NM_183416 & Charcot-Marie-Tooth neuropathy type 2A KIF1B 605995 1p36 & $3.00 \mathrm{e}-74$ & $1.00 \mathrm{e}-129$ & $1.00 \mathrm{e}-60$ & $4.00 \mathrm{e}-74$ \\
\hline SIX3 & NM_005413 & Holoprosencephaly type 2 SIX3 157170 2p21 & $6.00 e-79$ & $6.00 \mathrm{e}-61$ & $2.00 \mathrm{e}-48$ & $2.00 \mathrm{e}-85$ \\
\hline
\end{tabular}

${ }^{1}$ The Expect (E) value describes the probability due to chance that there is another alignment with a similarity greater than the given $\mathrm{S}$ score when searching a database of a particular size (in this case GeneBank_NR). It decreases exponentially as the S score of the match increases. An E <e-5 means that the alignment is highly unique; smaller numbers indicate greater chances of finding corresponding homologs (here, to human disease-related genes). An E value of 1 means that one can expect 1 match with a similar score simply by chance - see http://www.ncbi.nlm.nih.gov/BLAST/tutorial/Altschul-1.html.

pod/nematode clade. This figure illustrates that the evolutionary distance (represented by branch length) from Aplysia to mammals is shorter than the distance from either Drosophila or C. elegans to mammals. This indicates that the amino acid replacement rate has been lower in the lineage leading to Aplysia than in the lineages leading to Drosophila and C. elegans. Additional comparative analysis of evolutionarily conserved genes supports this hypothesis [Moroz et al., 2006]. Greater similarity was also found between mammalian and Aplysia proteins, confirming that the amino acid replacement rate has been lower in the molluscan lineage than in the lineages leading to Drosophila and C. elegans.

The initial analysis of Aplysia gene families revealed unexpected examples of gene loss in Drosophila and C. elegans from a common ancestor of bilaterian animals. Indeed, following the phylogeny outlined in figure $1 \mathrm{~A}$, the presence of a gene ortholog shared between Aplysia and mammals, combined with its absence from the genomes of Drosophila or C. elegans, indicate a loss of the orthologs in these lineages rather than its improbable independent origins in molluscs and deuterostomes. Consequently, less derived characteristics of the Aplysia genome might explain a greater conservation of genes related to development (e.g., the transcription factor Churchill), immunity, and human disease in Aplysia [Moroz et al., 2006; Panchin and Moroz, 2008] compared to Drosophila and C. elegans. This suggests that efforts to discern molecular and cellular functions of numerous genes related to human disease could eventually make greater use of Aplysia than Drosophila or C. elegans as model systems.

Table 1 lists some of the human disease-related genes found in the Aplysia transcriptome. Using an annotated subset of neuronal transcripts, numerous orthologs of genes implicated in more than a hundred neurological diseases were identified, including genes relevant to Parkinson's disease (e.g., Parkin) and Alzheimer's disease (e.g., presenilins and amyloid precursor protein), as well as fragile $\mathrm{X}$ mental retardation protein, huntingtin, the aging-related hormone Klotho, cytokines, and inflam- 
mation-related transcripts [Moroz et al., 2006]. Although research on the functions of such genes in molluscs has just begun [e.g., Lee et al., 2003], expression patterns of these genes in identified neurons will suggest avenues for further study. For example, huntingtin is expressed in specific motor neurons, where it is co-localized with FMRFamide and ACh (fig. 1C, D). Also biomedically interesting is a gene for $\mathrm{P} 2 \mathrm{X}$ receptors, ATP-gated channels that activate nociceptors to elicit pain in mammals [Burnstock, 2008]. These are expressed in particular neurons in Aplysia, but the functions of these neurons and receptors have yet to be investigated.

A promising advantage of Aplysia as a model organism is the presence of DNA methylation [Moroz et al., 2006; Moroz and Kohn, unpubl. observ.]. Cytosine methylation is thought to play a key role in epigenetic regulatory processes including the silencing of transposons, $\mathrm{X}$-chromosome inactivation, and imprinting. The DNA methyltransferase DNMT1, a crucial protein in this process, is responsible for the maintenance of $\mathrm{CpG}$ methylation and has been found in flowering plants, deuterostomes, and a subset of protostomes [Goll and Bestor, 2005]. Surprisingly, DNMT1 and DNA methyltransferases in general are lacking in C. elegans, Schistosoma [Rae and Steele, 1979; Fantappie et al., 2001], and Diptera [Goll and Bestor, 2005; Goll et al., 2006], all of which have only trace levels, if any, of 5-methyl cytosine at CpG sites [Rae and Steele, 1979; Simpson et al., 1986; Suzuki and Bird, 2008]. Homologs for DNMT1, DMAP1 (DNA methyltransferase associating protein), and the transcriptional repressor MBD2 (methyl-CpG-binding domain protein 2) were found in the Aplysia EST database and genome, demonstrating fundamental components of the $\mathrm{CpG}$ methylation machinery in Aplysia. Recent data indicate that chromatin remodeling and DNA methylation are involved in memory [Levenson et al., 2006] and possibly in chronic pain [Hosea Blewett, 2008].

These three features are not exclusive to Aplysia; large neurons, neurological disease-related genes, and cellular components for DNA methylation are found in other gastropods, including Tritonia, Pleurobranchaea, Clione, and Lymnaea, and the cephalopod molluscs, Octopus and Nautilus [Moroz and Kohn, unpubl. observ.]. Integration of genomics and physiological studies in individual, functionally characterized neurons in molluscs offers a powerful comparative approach to address molecular and cellular aspects of selected neurological problems.

Clearly, disorders at the network and systems levels contributing to complex neurological diseases are un- likely to be informed by network and systems properties of molluscan nervous systems, which display striking differences from those of other phyla at higher levels of organization. On the other hand, human disorders emanating from cellular and molecular properties of individual neurons that have the same functions in molluscs and mammals can be illuminated by comparisons across these phyla. In the following sections, we discuss similarities between long-term, injury-related plasticity of molluscan and mammalian nociceptors. These similarities point to evolutionarily conserved mechanisms important for both chronic pain and memory.

\section{Long-Term Nociceptive Sensitization in Molluscs: Functional Similarities to Chronic Pain in Mammals}

Most animals exhibit defensive behavioral responses to noxious (damaging or potentially damaging) stimuli. Despite the diversity of body plans and behaviors across Metazoa, ensembles of nociceptive responses often show common patterns [Walters, 1994]. These include rapid local withdrawal followed by escape responses that are accompanied by inhibition of behaviors, such as feeding, that can interfere with escape. Typically, these active defensive behaviors are followed by prolonged immobility and enhanced vigilance, as indicated by sensitization of subsequent defensive responses. This nociceptive sensitization magnifies subsequent responses to innocuous and noxious stimuli, and lowers response thresholds so that innocuous stimuli come to elicit responses that normally would only be evoked by noxious stimuli. Magnified defensive responses (withdrawal and escape locomotion) during nociceptive sensitization have been examined extensively in gastropod molluscs [e.g., Carew et al., 1971; Balaban, 1980; Walters, 1987b]. Moreover, the appearance of new defensive responses to innocuous stimulation during nociceptive sensitization has also been observed in Aplysia [Erickson and Walters, 1988]. These sensitizing effects in molluscs [Walters, 1987a, 1994] are formally similar to the alterations of defensive responses in mammals that are used experimentally as indices for pain hypersensitivity following prior noxious stimulation; i.e., hyperalgesia, defined as an enhancement of normal pain responses to noxious stimuli, and allodynia, defined as the elicitation of pain by normally innocuous stimuli.

Pain is defined as an unpleasant sensory and emotional experience associated with actual or potential tissue damage [Merskey and Bogduk, 1994]. Behavioral indices 
of pain are used because the subjective component cannot be measured directly. The sensory (nociceptive) component is also a necessary part of the human pain experience under most conditions, and these mechanisms can be determined experimentally and compared across phyla [Walters, 2008]. Investigation of nociceptive mechanisms has begun in a few invertebrates, including the leech [Nicholls and Baylor, 1968; Pastor et al., 1996], Drosophila [Tracey et al., 2003; Babcock et al., 2009], C. elegans [reviewed by Tobin and Bargmann, 2004] and, as described below, Aplysia.

Human pain caused by injury usually persists no longer than the period of healing. Such pain is generally considered to be adaptive, as suggested by the high morbidity and short lives of the rare individuals born without functioning nociceptors [Woolf and Ma, 2007]. In contrast to acute pain, chronic pain can persist long after apparent healing, bringing no obvious benefit to sufferers. Chronic pain is quite common, occurring in $\sim 20 \%$ of the world's population [Breivik et al., 2006], and it remains highly resistant to treatment. Mechanisms underlying the persistence of chronic pain are unknown; however, some forms of chronic pain are associated with persistent hyperexcitability of nociceptors, which might play a large role in driving such pain [Ali et al., 1999; Sung and Ambron, 2004; Ochoa et al., 2005; Shim et al., 2005; Walters, 2008; Walters et al., 2008]. As reviewed below, in Aplysia long-term hyperexcitability (LTH) of nociceptors has been associated with a form of memory, long-term sensitization of defensive behavior.

Mechanosensory neurons comprising the left E (LE) cluster in the abdominal ganglion [Byrne et al., 1974] and the ventrocaudal (VC) cluster in each pleural ganglion [Walters et al., 1983] have been investigated intensively in studies of learning and memory mechanisms [see Kandel, 2001]. Somata in the large, apparently homogeneous pleural VC clusters conveniently form a somatotopic map of the ipsilateral body surface, an 'aplunculus' (fig. 1B) [Walters et al., 2004]. Although the VC neurons and LE neurons (which innervate the siphon) are often regarded as receptors for light touch by investigators of learning and memory [e.g., Antonov et al., 2001], there are two reasons why these primary sensory neurons are properly considered to be nociceptors. First, except when sensitized, they exhibit relatively high thresholds, graded responses to increasing stimulus intensities, and maximal responses to pinching stimuli that cause clear tissue damage. Second, these cells share a property that among mechanosensory neurons is unique to nociceptors - sensitization to repeated stimulation (fig. 2B); other mecha- nosensory neurons adapt without sensitizing when repeatedly activated [Illich and Walters, 1997]. This sensitization by prior noxious stimulation, along with maximal activation by noxious stimuli, are characteristic features of nociceptors [Woolf and Ma, 2007].

Another similarity between rat and Aplysia nociceptors is their shared capacity to store long-term cellular 'memory' of noxious stimulation. Persistent inflammatory signals impinging on peripheral branches of nociceptors, rather than long-term alterations intrinsic to the nociceptors, are often assumed to drive persistent pain in mammals [e.g., Marchand et al., 2005]. Peripheral injury and inflammation alter gene expression within nociceptors, however, upregulating some ion channels and growth factor receptors [Waxman et al., 1994; Mannion et al., 1999; Woolf and Costigan, 1999; Ji et al., 2002]. Moreover, peripheral nerve injury and inflammation produce regenerative and collateral growth of nociceptor axons [Shea and Perl, 1985; Doucette and Diamond, 1987; $\mathrm{Lu}$ and Richardson, 1991] and a transcription-dependent enhancement of the nociceptor's growth state that continues to be expressed in vitro after isolation of the neurons [Smith and Skene, 1997]. In addition, LTH of dissociated sensory neurons following prior injury or inflammation has been documented [Ma and LaMotte, 2005; Walters et al., 2008]. Although such observations provide strong evidence for intrinsic cellular 'memory', they do not exclude the possibility that the memory lasts only long enough to amplify LTH initiated by the trauma of dissociation [Zheng et al., 2007].

Evidence that Aplysia sensory neurons display longterm alterations such as those associated with hyperalgesia in mammalian nociceptors came with the finding that nociceptors activated intensely by tail shock display synaptic facilitation and hyperexcitability of their cell soma lasting at least a day (fig. 2C) [Walters, 1987a]. Peripheral injury, produced by either pinching and cutting the tail or by crushing the nerve that innervates the tail, produces effects on the nociceptors that last weeks or longer. These include axonal regeneration [Steffensen et al., 1995] and sprouting of neurites near a site of peripheral injury and within central ganglia [Billy and Walters, 1989; Steffensen et al., 1995]. Peripheral injury also causes a decrease in mechanosensory threshold in the damaged region [Billy and Walters, 1989; Dulin et al., 1995], a decrease in electrical threshold of the nociceptor axon near a site of injury or of intense, transient depolarization [Weragoda et al., 2004], and an increase in excitability of the nociceptor soma [Walters et al., 1991]. Soma hyperexcitability promotes afterdischarge (fig. 2C) to afferent 


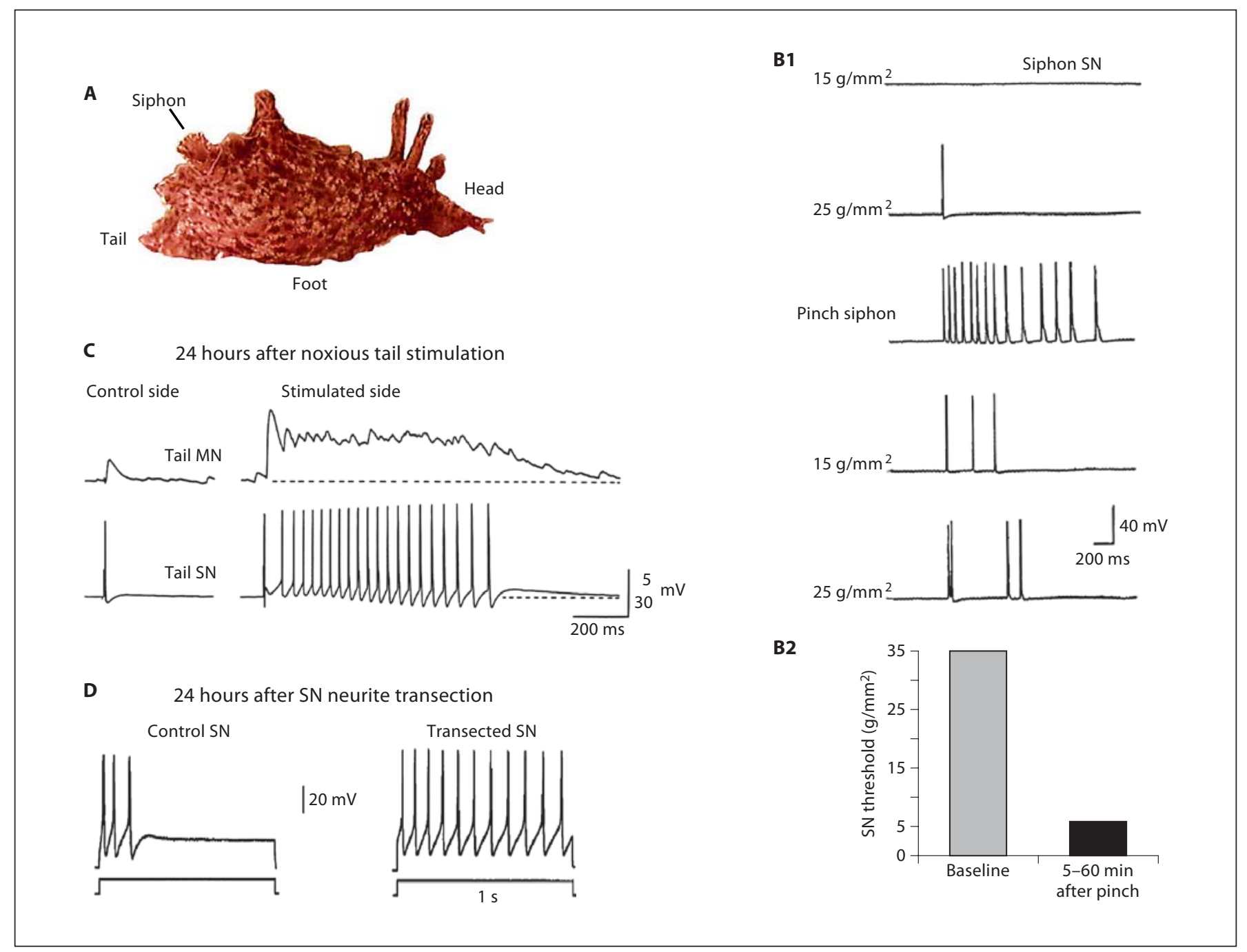

Fig. 2. Sensorin-expressing neurons in Aplysia are 'true' nociceptors and exhibit long-term nociceptive sensitization. A Body regions innervated by different sensory clusters. Sensory neurons innervating the siphon (LE cluster) and tail (VC cluster) have received the most study. B Evidence that mechanosensory neurons are nociceptors. Responses of an LE siphon sensory neuron (SN) to mechanical stimulation (B1) exhibit a relatively high threshold, are maximal with damaging stimuli (pinch), and increase (sensitize) following the pinch (B1 and B2) [modified from Illich and Walters, 1997]. C Long-term, sensitizing effects in a nociceptive

action potentials, amplifying nociceptive input to the CNS [Gasull et al., 2005]. Finally, peripheral injury can produce synaptic facilitation (fig. 2C) [Walters et al., 1991]. The existence of intrinsic mechanisms for hyperexcitability in Aplysia nociceptors is demonstrated by the induction of LTH in isolated, dissociated neurons by transection of their neurites (fig. 2D) [Ambron et al., tail sensory neuron. One day after noxious tail shock a SN innervating the shocked site, but not a contralateral control SN, exhibited afterdischarge following a brief $(10-\mathrm{msec})$ test pulse to the soma, and pronounced facilitation of its synapse onto a tail motor neuron (MN) [modified from Walters, 1987b]. D Intrinsic injury signals are sufficient to produce SN hyperexcitability. Example showing how the spike accommodation normally seen in control SNs is greatly reduced in a dissociated SN one day after transection of its neurites [modified from Ambron et al., 1996].

1996; Bedi et al., 1998] or transient depolarization [Kunjilwar et al., 2009]. Additional evidence comes from the expression of LTH after peripheral injury or transient depolarization in ganglia-nerve preparations under low$\mathrm{Ca}^{2+}$ conditions likely to block continuing release of neuromodulators [Weragoda et al., 2004; Gasull et al., 2005; Kunjilwar et al., 2009]. 
Functional similarities of long-term plasticity in Aplysia and rat nociceptors after injury suggested that severe noxious stimulation might switch diverse types of nociceptors into a persistent, intrinsically maintained hyperfunctional state. This idea is being tested in a rat model of chronic pain induced by spinal cord injury. Chronic neuropathic pain after central damage, which occurs in a majority of human patients after spinal cord injury, was not previously thought to involve changes in nociceptors. A novel prediction was that prolonged exposure of the central axons and terminals of nociceptors to signs of tissue injury (e.g., inflammatory signals) would lead to LTH that could result in persistent spontaneous activity being generated in nociceptor somata (and enhanced growth of their processes), even when isolated from extrinsic inputs. Preliminary support for this prediction [Walters et al., 2008] raises the possibility that nociceptors might be a useful target for treating this often intractable form of chronic pain.

\section{Did Fundamental Mechanisms Underlying Memory and Chronic Pain Evolve from Ancestral Responses to Peripheral Injury?}

Striking similarities exist in the behavioral and cellular responses of Aplysia, rats, and other animals to noxious stimulation [Walters, 1994, 2008]. Furthermore, these similarities are paralleled by functional similarities in their nociceptors. The similarities are likely to reflect contributions both from convergent, independently derived mechanisms and from ancestral, evolutionarily conserved (homologous), molecular mechanisms. Here we review evidence for shared signaling pathways that induce nociceptive plasticity, point out that these apparently homologous signals also play roles in triggering long-term memory in the CNS, and discuss peripheral injury as a ubiquitous selection pressure that might have shaped ancestral plasticity mechanisms.

Both in nociceptors and memory circuits, plasticity mechanisms cause short- and long-term neuronal alterations: enhancement of synaptic transmission [e.g., Ji et al., 2003; Lee and Silva, 2009], enhancement of membrane excitability [e.g., Xu and Kang, 2005; Devor, 2006], and growth or regrowth of synapses and processes [Bailey and Kandel, 2008; De Roo et al., 2008]. These alterations are induced by numerous signals that are common to Aplysia sensorimotor systems, mammalian spinal sensory systems, and mammalian circuits in the hippocampus and other parts of the brain important for learning and memory. Some of the general initiating signals that are common to molluscan and mammalian nociceptors, and to neurons displaying long-term plasticity in central neurons of diverse animals are shown in figure 3. Initiating events for long-term alterations include intense depolarization and $\mathrm{Ca}^{2+}$ entry consequent to membrane injury or binding of excitatory amino acids, and activation of cell signaling pathways by binding of neuromodulators and growth factors released by neurons [Jankowsky and Patterson, 1999; Kandel, 2001; Weragoda and Walters, 2007] and other cell types [e.g., glia, support cells, and inflammatory cells; Bradley and Finkbeiner, 2002; Gibbs et al., 2008]. Changes in gene expression are triggered by $\mathrm{Ca}^{2+}$ entry accompanying action potentials propagating into the soma [Saha and Dudek, 2008], as well as retrograde signals transported to the nucleus from sites of axonal injury [Gunstream et al., 1995; Ambron and Walters, 1996; Lin et al., 2003; Sung and Ambron, 2004] or intense synaptic stimulation [Otis et al., 2006; Lai et al., 2008]. Long-term alterations can include effects localized to sites of injury or to intensely activated synapses, as well as global actions affecting much of the neuron from neural or endocrine signals released throughout the body during either injury or the formation of central memories.

Intracellular plasticity signals common to injury and memory include $\mathrm{Ca}^{2+}$ entering through ionotropic glutamate receptor-gated channels opened during intense electrical activity [Moroz et al., 1993; Ji et al., 2003; Ha et al., 2006; Rao and Finkbeiner, 2007; Glanzman, 2008], and activation of cell signaling pathways by $\mathrm{Ca}^{2+}$ transients and by the binding of ligands to G-protein-coupled receptors and receptor tyrosine kinases [Ji et al., 2003; Purcell and Carew, 2003; Barco et al., 2006; Pezet and McMahon, 2006; Lu et al., 2008]. The known downstream signals associated with injury and memory are also highly conserved, including activated protein kinase or lipid kinase enzymes, notably PKA, PKC, ERK and PI3K [Obata and Noguchi, 2004; Barco et al., 2006; Cheng and Ji, 2008; Sossin, 2008; Lee and Silva, 2009]. Less extensive evidence suggests that NO, cGMP, and PKG [Aley et al., 1998; Lewin and Walters, 1999; Sung and Ambron, 2004; Sung et al., 2004; Zheng et al., 2007; Antonov et al., 2007; Ota et al., 2008] and a protein kinase, TOR (mTOR in mammals), which promotes local protein synthesis in axons and dendrites [Casadio et al., 1999; Weragoda et al., 2004; Hu et al., 2007; Price et al., 2007; Jimenez-Diaz et al., 2008; Sossin, 2008; Costa-Mattioli et al., 2009], also contribute to both nociceptor sensitization and conventional memory. Long-term effects usually require chang- 


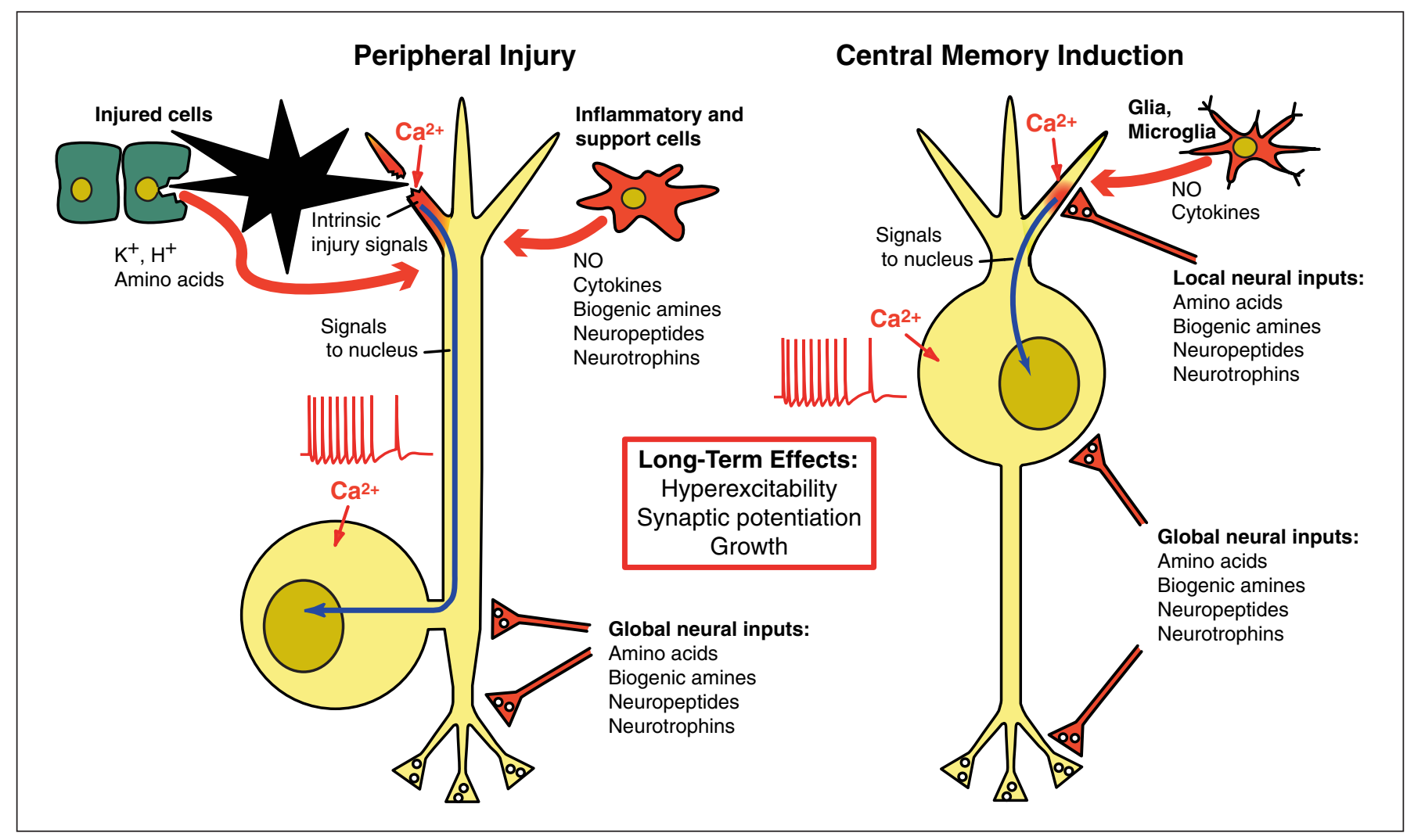

Fig. 3. Similarity of initial signals for induction of long-term neuronal plasticity in molluscan and mammalian nociceptors (left side) and mammalian neurons that form memories within the CNS (right side). In each case local signals include intense depolarization of an injured segment or synaptic region (darkened areas), $\mathrm{Ca}^{2+}$ influx, and modulation by various neuroactive sub-

es in gene transcription, with the transcription factor CREB playing an important role in prominent forms of long-term plasticity in mammalian brain [Alberini, 2009; Lee and Silva, 2009] and Aplysia nociceptors [Casadio et al., 1999; Lewin and Walters, 1999; Barco et al., 2006], and play a role in nociceptive plasticity of mammalian nociceptors as well [Tamura et al., 2005; Teng and Tang, 2006]. Thus, at the subcellular and molecular levels, induction mechanisms for long-term plasticity appear remarkably similar when comparing molluscs to mammals, and comparing nociceptors to hippocampal neurons.

These molecular similarities support the proposal that fundamental mechanisms important for memory and chronic pain evolved from adaptive responses to injury in the earliest animals [Walters, 1991]. Injury-related selection pressures might be both powerful and ubiquitous; an animal that after injury cannot compensate for loss of stances released from nearby cells. In addition, global signals released during injury or memorable events can influence the soma and other parts of the neuron, at least in part by regulating gene transcription. These initiating events for nociceptive sensitization and memory are mediated by common sets of highly conserved intracellular signals (see text). sensory function or utilize nociceptive sensitization to reduce chances of further injury is likely to be less successful biologically than one that does. Unlike pressures to store information about changes in the environment or about consequences of behavioral actions, which would have had little impact until neural circuits complex enough to store such information had evolved, injury-related selection pressures have probably operated on neurons (and antecedent cells) from the earliest stages of animal evolution. In other words, plasticity mechanisms selected as adaptive responses to injury could have appeared long before the origin of nervous systems complex enough to support forms of learning and memory involving the integration of diverse sources of information (e.g., associative learning).

It seems likely that the earliest neurons were cells with both sensory and motor functions in small early metazo- 
ans that lacked shells or hard exoskeletons. Branches of these neurons would have been exposed directly to peripheral trauma from inanimate, and possibly animate, sources. Thus, plasticity mechanisms might have been selected in early neurons for their ability to (1) repair and regenerate damaged axonal branches, (2) compensate for loss of sensory function within a damaged region, (3) protect against self-inflicted damage (e.g., by suppressing movements of body parts with open wounds), and (4) boost responses to attacks by predators or parasites attracted by a wound [Walters, 1991, 1994; Weragoda et al., 2004]. The first set of mechanisms would result in regrowth of lost axonal branches, and the other sets could include (1) hyperexcitability of an injured neuron's surviving branches, (2) hyperexcitability of the branches of nearby, undamaged sensory neurons, (3) hyperexcitability of the soma or central branches of sensory neurons (which could amplify trains of sensory action potentials arriving from the periphery), (4) enhanced release of neurotransmitters from central synapses of sensory neurons, and (5) growth of new synapses from surviving sensory neurons.

None of the molecular signals and cellular effectors associated thus far with nociceptor plasticity or with memory is restricted to neuronal plasticity; each has many other roles and is found in most metazoan cells. Known molecular signals identified with neuronal plasticity (second messengers, protein kinases, protein phosphatases, transcription factors) represent parts of highly conserved, core regulatory modules [e.g., Gerhart and Kirschner, 1997], which are also widely involved in devel- opment, differentiation, adaptation to different physiological conditions, and cellular responses to stress. In primeval neurons, signaling modules activated by signs of cellular damage or tissue injury (e.g., extracellular exposure to $\mathrm{K}^{+}$, amino acids, and other intracellular constituents released from ruptured cells, depolarization, $\mathrm{Ca}^{2+}$ influx - see fig. 3) might have become linked to cellular effectors that could mount the adaptive neuronal responses described above. An intriguing possibility is that injury-activated plasticity systems, selected early in evolution for peripheral functions, were 'pre-adapted' for later use in more complex, central forms of neural plasticity. In the CNS such plasticity would then be activated by normal and pathological release of intercellular signals - such as glutamate and growth factors - that were signs of tissue injury in the first multicellular organisms, and later became adapted for signaling between neurons as nervous systems evolved. Comparative studies across Mollusca and other phyla will be important for testing such evolutionary hypotheses, and should offer insights into the functions and dysfunctions of highly conserved plasticity systems that might be shared with humans.

\section{Acknowledgements}

We are grateful to Drs. Robyn Crook and Paul Katz for helpful comments. E.T.W. is supported by NIH grants 1RO1NS3599 and R21NS061200, and a grant from the Christopher Reeve Foundation. L.L.M. is supported by NIH and NSF grants 1RO1NS06076, R21RR025699, NSF-0744649, and in part by the McKnight Brain Research Foundation and UF Opportunity Funds.

\section{References}

Adams DJ, Smith SJ, Thompson SH (1980) Ionic currents in molluscan soma. Annu Rev Neurosci 3:141-167.

-Alberini CM (2009) Transcription factors in long-term memory and synaptic plasticity. Physiol Rev 89:121-145.

-Aley KO, McCarter G, Levine JD (1998) Nitric oxide signaling in pain and nociceptor sensitization in the rat. J Neurosci 18:70087014.

-Ali Z, Ringkamp M, Hartke TV, Chien HF, Flavahan NA, Campbell JN, Meyer RA (1999) Uninjured C-fiber nociceptors develop spontaneous activity and alpha-adrenergic sensitivity following L6 spinal nerve ligation in monkey. J Neurophysiol 81:455-466.
Ambron RT, Walters ET (1996) Priming events and retrograde injury signals. A new perspective on the cellular and molecular biology of nerve regeneration. Mol Neurobiol 13:61-79.

Ambron RT, Zhang XP, Gunstream JD, Povelones M, Walters ET (1996) Intrinsic injury signals enhance growth, survival, and excitability of Aplysia neurons. J Neurosci 16: 7469-7477.

Antonov I, Antonova I, Kandel ER, Hawkins RD (2001) The contribution of activity-dependent synaptic plasticity to classical conditioning in Aplysia. J Neurosci 21:64136422.

-AntonovI,Ha T, Antonova I, MorozLL, Hawkins, RD (2007) Role of nitric oxide in classical conditioning of siphon withdrawal in Aplysia. J Neurosci 27:10993-11002
Babcock DT, Landry C, Galko MJ (2009) Cytokine signaling mediates UV-induced nociceptive sensitization in Drosophila larvae. Curr Biol 19:799-806.

- Bailey CH, Kandel ER (2008) Synaptic remodeling, synaptic growth and the storage of longterm memory in Aplysia. Prog Brain Res 169: 179-198.

Balaban PM (1980) Sensitization and habituation in command neurons of the defensive reflex in Helix lucorum. Neurosci Behav Physiol 10:340-345.

- Barco A, Bailey CH, Kandel ER (2006) Common molecular mechanisms in explicit and implicit memory. J Neurochem 97:1520-1533. 
Bedi SS, Salim A, Chen S, Glanzman DL (1998) Long-term effects of axotomy on excitability and growth of isolated Aplysia sensory neurons in cell culture: potential role of cAMP. J Neurophysiol 79:1371-1383.

- Billy AJ, Walters ET (1989) Long-term expansion and sensitization of mechanosensory receptive fields in Aplysia support an activity-dependent model of whole-cell sensory plasticity. J Neurosci 9:1254-1262.

- Bradley J, Finkbeiner S (2002) An evaluation of specificity in activity-dependent gene expression in neurons. Prog Neurobiol 67:469477.

Breivik H, Collett B, Ventafridda V, Cohen R, Gallacher D (2006) Survey of chronic pain in Europe: prevalence, impact on daily life, and treatment. Eur J Pain 10:287-333.

- Burnstock G (2008) Purinergic signalling and disorders of the central nervous system. Nat Rev Drug Discov 7:575-590.

- Byrne J, Castellucci V, Kandel ER (1974) Receptive fields and response properties of mechanoreceptor neurons innervating siphon skin and mantle shelf in Aplysia. J Neurophysiol 37:1041-1064.

- Carew TJ, Castellucci VF, Kandel ER (1971) An analysis of dishabituation and sensitization of the gill-withdrawal reflex in Aplysia. Int J Neurosci 2:79-98.

-Casadio A, Martin KC, Giustetto M, Zhu H, Chen M, Bartsch D, Bailey CH, Kandel ER (1999) A transient, neuron-wide form of CREB-mediated long-term facilitation can be stabilized at specific synapses by local protein synthesis. Cell 99:221-237.

Cash D, Carew TJ (1989) A quantitative analysis of the development of the central nervous system in juvenile Aplysia californica. J Neurobiol 20:25-47.

Chase RB (2002) Behavior and its neural control in gastropod molluscs. Oxford, UK: Oxford University Press.

-Cheng JK, Ji RR (2008) Intracellular signaling in primary sensory neurons and persistent pain. Neurochem Res 33:1970-1978.

-Costa-Mattioli M, Sossin WS, Klann E, Sonenberg N (2009) Translational control of longlasting synaptic plasticity and memory. Neuron 61:10-26.

De Roo M, Klauser P, Garcia PM, Poglia L, Muller D (2008) Spine dynamics and synapse remodeling during LTP and memory processes. Prog Brain Res 169:199-207.

-Devor M (2006) Sodium channels and mechanisms of neuropathic pain. J Pain 7:S3-S12.

Doucette R, Diamond J (1987) Normal and precocious sprouting of heat nociceptors in the skin of adult rats. J Comp Neurol 261:592603.

-Drake TJ, Jezzini S, Lovell P, Moroz LL, Tan W (2005) Single cell glutamate analysis in Aplysia sensory neurons. J Neurosci Methods 144:73-77.
Dulin MF, Steffensen I, Morris CE, Walters ET (1995) Recovery of function, peripheral sensitization and sensory neurone activation by novel pathways following axonal injury in Aplysia californica. J Exp Biol 198:20552066

Erez H, Spira ME (2008) Local self-assembly mechanisms underlie the differential transformation of the proximal and distal cut axonal ends into functional and aberrant growth cones. J Comp Neurol 507:1019-1030.

Erickson MT, Walters ET (1988) Differential expression of pseudoconditioning and sensitization by siphon responses in Aplysia: novel response selection after training. J Neurosci 8:3000-3010

Fantappie MR, Gimba ER, Rumjanek FD (2001) Lack of DNA methylation in Schistosoma mansoni. Exp Parasitol 98:162-166.

Gasull X, Liao X, Dulin MF, Phelps C, Walters ET (2005) Evidence that long-term hyperexcitability of the sensory neuron soma in duced by nerve injury in Aplysia is adaptive. J Neurophysiol 94:2218-2230.

Gerhart J, Kirschner M (1997) Cells, Embryos, and Evolution: Toward a cellular and developmental understanding of phenotypic variation and evolutionary adaptability. Malden, MA: Blackwell Publishers.

-Gibbs ME, Hutchinson D, Hertz L (2008) Astrocytic involvement in learning and memory consolidation. Neurosci Biobehav Rev 32: 927-944.

Gilbert DL, Adelman WJ, Arnold JM (1990) Squid as experimental animals. New York, NY: Plenum Press.

Gitler D, Spira ME (1998) Real time imaging of calcium-induced localized proteolytic activity after axotomy and its relation to growth cone formation. Neuron 20:1123-1135.

Glanzman DL (2008) New tricks for an old slug: the critical role of postsynaptic mechanisms in learning and memory in Aplysia. Prog Brain Res 169:277-292.

Goll MG, Bestor TH (2005) Eukaryotic cytosine methyltransferases. Annu Rev Biochem 74: 481-514

Goll MG, Kirpekar F, Maggert KA, Yoder JA, Hsieh CL, Zhang X, Golic KG, Jacobsen SE, Bestor TH (2006) Methylation of tRNAAsp by the DNA methyltransferase homolog Dnmt2. Science 311:395-398.

Gunstream JD, Castro GA, Walters ET (1995) Retrograde transport of plasticity signals in Aplysia sensory neurons following axonal injury. J Neurosci 15:439-448.

- Ha TJ, Kohn AB, Bobkova YV, Moroz LL (2006) Molecular characterization of NMDA-like receptors in Aplysia and Lymnaea: relevance to memory mechanisms. Biol Bull 210:255270.

Hosea Blewett HJ (2008) Exploring the mechanisms behind S-adenosylmethionine (SAMe) in the treatment of osteoarthritis. Crit Rev Food Sci Nutr 48:458-463.
Hu JY, Chen Y, Schacher S (2007) Protein kinase $\mathrm{C}$ regulates local synthesis and secretion of a neuropeptide required for activity-dependent long-term synaptic plasticity. J Neurosci 27:8927-8939.

- Illich PA, Walters ET (1997) Mechanosensory neurons innervating Aplysia siphon encode noxious stimuli and display nociceptive sensitization. J Neurosci 17:459-469.

-Jankowsky JL, Patterson PH (1999) Cytokine and growth factor involvement in long-term potentiation. Mol Cell Neurosci 14:273286.

Jezzini SH, Bodnarova M, Moroz LL (2005) Twocolor in situ hybridization in the CNS of $A p$ lysia californica. J Neurosci Methods 149: $15-25$.

-Ji RR, Kohno T, Moore KA, Woolf CJ (2003) Central sensitization and LTP: do pain and memory share similar mechanisms? Trends Neurosci 26:696-705.

- Ji RR, Samad TA, Jin SX, Schmoll R, Woolf C) (2002) p38 MAPK activation by NGF in primary sensory neurons after inflammation increases TRPV1 levels and maintains heat hyperalgesia. Neuron 36:57-68.

-Jimenez-Diaz L, Geranton SM, Passmore GM, Leith JL, Fisher AS, Berliocchi L, Sivasubramaniam AK, Sheasby A, Lumb BM, Hunt SP (2008) Local translation in primary afferent fibers regulates nociception. PLoS ONE 3: e1961.

Kandel ER (1976) Cellular Basis of Behavior. San Francisco, CA: W.H. Freeman and Company.

Kandel ER (2001) The molecular biology of memory storage: a dialogue between genes and synapses. Science 294:1030-1038.

-Knudsen B, Kohn AB, Nahir B, McFadden CS, Moroz LL (2006) Complete DNA sequence of the mitochondrial genome of the sea-slug, Aplysia californica: conservation of the gene order in Euthyneura. Mol Phylogenet Evol 38:459-469.

Kunjilwar KK, Fishman HM, Englot DJ, O’Neil RG, Walters ET (2009) Long-lasting hyperexcitability induced by depolarization in the absence of detectable Ca2+ signals. J Neurophysiol 101:1351-1360.

- Lai KO, Zhao Y, Ch'ng TH, Martin KC (2008) Importin-mediated retrograde transport of CREB2 from distal processes to the nucleus in neurons. Proc Natl Acad Sci USA, 105: 17175-17180.

Lee JA, Lim CS, Lee SH, Kim H, Nukina N, Kaang BK (2003) Aggregate formation and the impairment of long-term synaptic facilitation by ectopic expression of mutant huntingtin in Aplysia neurons. J Neurochem 85: 160-169.

Lee YS, Silva AJ (2009) The molecular and cellular biology of enhanced cognition. Nat Rev Neurosci 10:126-140. 
-Levenson JM, Roth TL, Lubin FD, Miller CA, Huang IC, Desai P, Malone LM, Sweatt JD (2006) Evidence that DNA (cytosine-5) methyltransferase regulates synaptic plasticity in the hippocampus. J Biol Chem 281: 15763-15773.

Lewin MR, Walters ET (1999) Cyclic GMP pathway is critical for inducing long-term sensitization of nociceptive sensory neurons. Nat Neurosci 2:18-23.

- Lin H, Bao J, Sung YJ, Walters ET, Ambron RT (2003) Rapid electrical and delayed molecular signals regulate the serum response element after nerve injury: convergence of injury and learning signals. J Neurobiol 57: 204-220.

- Lovell P, Jezzini SH, Moroz LL (2006) Electroporation of neurons and growth cones in Aplysia californica. J Neurosci Methods 151: 114-120.

Lovell P, Moroz LL (2006) The largest growth cones in the animal kingdom and dynamics of neuronal growth in cell culture of Aplysia. Int Comp Biol 46:847-870.

Lu X, Richardson PM (1991) Inflammation near the nerve cell body enhances axonal regeneration. J Neurosci 11:972-978.

Lu Y, Christian K, Lu B (2008) BDNF: a key regulator for protein synthesis-dependent LTP and long-term memory? Neurobiol Learn Mem 89:312-323.

- Ma C, LaMotte RH (2005) Enhanced excitability of dissociated primary sensory neurons after chronic compression of the dorsal root ganglion in the rat. Pain 113:106-112.

-Mannion RJ, Costigan M, Decosterd I, Amaya F, Ma QP, Holstege JC, Ji RR, Acheson A, Lindsay RM, Wilkinson GA, Woolf CJ (1999) Neurotrophins: peripherally and centrally acting modulators of tactile stimulus-induced inflammatory pain hypersensitivity. Proc Natl Acad Sci USA 96:9385-9390.

-Marchand F, Perretti M, McMahon SB (2005) Role of the immune system in chronic pain. Nat Rev Neurosci 6:521-532.

Merskey H, Bogduk N (1994) Part III: pain terms, a current list with definitions and notes on usage. In: Classification of chronic pain, IASP task force on taxonomy (Merskey $\mathrm{H}$, Bogduk N, eds), pp 209-214. Seattle, WA: IASP Press.

Moccia R, Chen D, Lyles V, Kapuya E, E Y, Kalachikov S, Spahn CM, Frank J, Kandel ER, Barad M, Martin KC (2003) An unbiased cDNA library prepared from isolated Aplysia sensory neuron processes is enriched for $\mathrm{cy}$ toskeletal and translational mRNAs. J Neurosci 23:9409-9417.

Moroz LL, Dahlgren RL, Boudko D, Sweedler JV, Lovell P (2005) Direct single cell determination of nitric oxide synthase related metabolites in identified nitrergic neurons. J Inorg Biochem 99:929-939.
Moroz LL, Edwards JR, Puthanveettil SV, Kohn AB, Ha T, Heyland A, Knudsen B, Sahni A, Yu F, Liu L, Jezzini S, Lovell P, Iannucculli W, Chen M, Nguyen T, Sheng H, Shaw R, Kalachikov S, Panchin YV, Farmerie W, Russo JJ, Ju J, Kandel ER (2006) Neuronal transcriptome of Aplysia: neuronal compartments and circuitry. Cell 127:1453-1467.

Moroz LL, Gyori J, Salanki J (1993) NMDA-like receptors in the CNS of molluscs. Neuroreport 4:201-204.

Moroz LL, Ju J, Russo JJ, Puthanveetti S, Kohn A, Medina M, Walsh PJ, Birren B, Lander ES, Kandel ER (2004) Sequencing the Aplysia genome: a model for single cell, real-time and comparative genomics. http://www.genome.gov/Pages/Research/Sequencing/SeqProposals/AplysiaSeq.pdf

- Nicholls JG, Baylor DA (1968) Specific modalities and receptive fields of sensory neurons in CNS of the leech. J Neurophysiol 31:740756.

- Obata K, Noguchi K (2004) MAPK activation in nociceptive neurons and pain hypersensitivity. Life Sci 74:2643-2653.

Ochoa JL, Campero M, Serra J, Bostock H (2005) Hyperexcitable polymodal and insensitive nociceptors in painful human neuropathy. Muscle Nerve 32:459-472.

Ota KT, Pierre VJ, Ploski JE, Queen K, Schafe GE (2008) The NO-cGMP-PKG signaling pathway regulates synaptic plasticity and fear memory consolidation in the lateral amygdala via activation of ERK/MAP kinase. Learn Mem 15:792-805.

-Otis KO, Thompson KR, Martin KC (2006) Importin-mediated nuclear transport in neurons. Curr Opin Neurobiol 16:329-335.

- Panchin Y, Moroz LL (2008) Molluscan mobile elements similar to the vertebrate recombination-activating genes. Biochem Biophys Res Commun 369:818-823.

- Pastor J, Soria B, Belmonte C (1996) Properties of the nociceptive neurons of the leech segmental ganglion. J Neurophysiol 75:22682279.

- Pezet S, McMahon SB (2006) Neurotrophins: mediators and modulators of pain. Annu Rev Neurosci 29:507-538.

- Price TJ, Rashid MH, Millecamps M, Sanoja R, Entrena JM, Cervero F (2007) Decreased nociceptive sensitization in mice lacking the fragile $\mathrm{X}$ mental retardation protein: role of mGluR1/5 and mTOR. J Neurosci 27:1395813967.

Purcell AL, Carew TJ (2003) Tyrosine kinases, synaptic plasticity and memory: insights from vertebrates and invertebrates. Trends Neurosci 26:625-630.

Rae PM, Steele RE (1979) Absence of cytosine methylation at C-C-G-G and G-C-G-C sites in the rDNA coding regions and intervening sequences of Drosophila and the rDNA of other insects. Nucleic Acids Res 6:29872995.
Rao VR, Finkbeiner S (2007) NMDA and AMPA receptors: old channels, new tricks. Trends Neurosci 30:284-291.

Saha RN, Dudek SM (2008) Action potentials: to the nucleus and beyond. Exp Biol Med (Maywood) 233:385-393.

- Samarova EI, Bravarenko NI, Korshunova TA, Gulyaeva NV, Palotas A, Balaban PM (2005) Effect of beta-amyloid peptide on behavior and synaptic plasticity in terrestrial snail. Brain Res Bull 67:40-45.

Satpute-Krishnan P, DeGiorgis JA, Bearer EL (2003) Fast anterograde transport of herpes simplex virus: role for the amyloid precursor protein of alzheimer's disease. Aging Cell 2: 305-318.

-Shea VK, Perl ER (1985) Regeneration of cutaneous afferent unmyelinated (C) fibers after transection. J Neurophysiol 54:502-512.

-Shemesh OA, Erez H, Ginzburg I, Spira ME (2008) Tau-induced traffic jams reflect organelles accumulation at points of microtubule polar mismatching. Traffic 9:458-471.

-Shim B, Kim DW, Kim BH, Nam TS, Leem JW, Chung JM (2005) Mechanical and heat sensitization of cutaneous nociceptors in rats with experimental peripheral neuropathy. Neuroscience 132:193-201.

- Simpson VJ, Johnson TE, Hammen RF (1986) Caenorhabditis elegans DNA does not contain 5-methylcytosine at any time during development or aging. Nucleic Acids Res 14: 6711-6719.

-Smith DS, Skene JH (1997) A transcription-dependent switch controls competence of adult neurons for distinct modes of axon growth. J Neurosci 17:646-658.

-Sossin WS (2008) Molecular memory traces. Prog Brain Res 169:3-25.

-Steffensen I, Dulin MF, Walters ET, Morris CE (1995) Peripheral regeneration and central sprouting of sensory neurone axons in Aplysia californica following nerve injury. J Exp Biol 198:2067-2078.

- Sung YJ, Ambron RT (2004) Pathways that elicit long-term changes in gene expression in nociceptive neurons following nerve injury: contributions to neuropathic pain. Neurol Res 26:195-203.

- Sung YJ, Walters ET, Ambron RT (2004) A neuronal isoform of protein kinase $\mathrm{G}$ couples mitogen-activated protein kinase nuclear import to axotomy-induced long-term hyperexcitability in Aplysia sensory neurons. J Neurosci 24:7583-7595.

-Suzuki MM, Bird A (2008) DNA methylation landscapes: provocative insights from epigenomics. Nat Rev Genet 9:465-476.

- Tamura S, Morikawa Y, Senba E (2005) Up-regulated phosphorylation of signal transducer and activator of transcription 3 and cyclic AMP-responsive element binding protein by peripheral inflammation in primary afferent neurons possibly through oncostatin $\mathrm{M}$ receptor. Neuroscience 133:797-806. 
Teng FY, Tang BL (2006) Axonal regeneration in adult CNS neurons - signaling molecules and pathways. J Neurochem 96:1501-1508.

- Tobin DM, Bargmann CI (2004) Invertebrate nociception: behaviors, neurons and molecules. J Neurobiol 61:161-174.

- Tracey WD Jr, Wilson RI, Laurent G, Benzer S (2003) painless, a Drosophila gene essential for nociception. Cell 113:261-273.

Valentine JW (2004) On the origin of phyla. Chicago, IL: University of Chicago Press.

-Walters ET (1987a) Multiple sensory neuronal correlates of site-specific sensitization in Aplysia. J Neurosci 7:408-417.

Walters ET (1987b) Site-specific sensitization of defensive reflexes in Aplysia: a simple model of long-term hyperalgesia. J Neurosci 7:400407.

-Walters ET (1991) A functional, cellular, and evolutionary model of nociceptive plasticity in Aplysia. Biol Bull 180:241-251.

-Walters ET (1994) Injury-related behavior and neuronal plasticity: an evolutionary perspective on sensitization, hyperalgesia, and analgesia. Int Rev Neurobiol 36:325-427.

Walters ET (2008) Evolutionary aspects of pain. In: The senses: a comprehensive reference, volume 5. Pain (Basbaum A, Bushnell CM, eds), pp 175-184. Burlington, MA: Academic Press/Elsevier.
Walters ET, Alizadeh H, Castro GA (1991) Similar neuronal alterations induced by axonal injury and learning in Aplysia. Science 253: 797-799.

Walters ET, Bodnarova M, Billy AJ, Dulin MF, Diaz-Rios M, Miller MW, Moroz LL (2004) Somatotopic organization and functional properties of mechanosensory neurons expressing sensorin-A mRNA in Aplysia californica. J Comp Neurol 471:219-240.

-Walters ET, Byrne JH, Carew TJ, Kandel ER (1983) Mechanoafferent neurons innervating tail of Aplysia. I. Response properties and synaptic connections. J Neurophysiol 50: 1522-1542.

Walters ET, Fishman HM, Yang Q, Du J, Bedi SS, Carlton SM, Grill RJ (2008) Spontaneous activity in small DRG neurons following spinal cord injury may contribute to chronic neuropathic pain. Soc Neurosci Abstr Viewer/Itinerary Planner, Program 368.21
Waxman SG, Kocsis JD, Black JA (1994) Type III sodium channel mRNA is expressed in embryonic but not adult spinal sensory neurons, and is reexpressed following axotomy. J Neurophysiol 72:466-470.

Weragoda RM, Ferrer E, Walters ET (2004) Memory-like alterations in Aplysia axons after nerve injury or localized depolarization. J Neurosci 24:10393-10401.

-Weragoda RM, Walters ET (2007) Serotonin induces memory-like, rapamycin-sensitive hyperexcitability in sensory axons of aplysia that contributes to injury responses. J Neurophysiol 98:1231-1239.

-Woolf CJ, Costigan M (1999) Transcriptional and posttranslational plasticity and the generation of inflammatory pain. Proc Natl Acad Sci USA 96:7723-7730.

-Woolf CJ, Ma Q (2007) Nociceptors - noxious stimulus detectors. Neuron 55:353-364.

Xu J, Kang J (2005) The mechanisms and functions of activity-dependent long-term potentiation of intrinsic excitability. Rev Neurosci 16:311-323.

- Zheng JH, Walters ET, Song XJ (2007) Dissociation of dorsal root ganglion neurons induces hyperexcitability that is maintained by increased responsiveness to cAMP and cGMP. J Neurophysiol 97:15-25. 